\title{
RESIKO PENGASUHAN PERMISIF ORANG TUA DAN NENEK PADA PENCAPAIAN BAHASA ANAK
}

\author{
Arifah Prima Satrianingrum ${ }^{1 *}$, Erna Andriyanti ${ }^{1}$ \\ 1Jurusan Pendidikan Anak Usia Dini, Fakultas Program Pascasarjana, \\ Universitas Negeri Yogyakarta, Yogyakarta 55281, Indonesia \\ *)E-mail: aprimasatrianingrum@yahoo.com
}

\begin{abstract}
Abstrak
Pencapaian bahasa anak dipengaruhi oleh beberapa faktor, salah satunya adalah pengasuhan orang tua. Penelitian ini mengkaji pencapaian bahasa anak usia 2 tahun pada sebuah keluarga di Samirono, Yogyakarta yang diasuh oleh orang tua dan nenek dengan pola asuh permisif. Tujuan penelitian ini adalah untuk mendeskripsikan resiko pengasuhan permisif yang diterapkan orang tua dan nenek pada pencapaian bahasa anak. Penelitian ini menggunakan model kualitatif dengan pendekatan studi kasus. Pengumpulan data menggunakan wawancara dan observasi. Informan dalam penelitian berjumlah empat orang yang dipilih menggunakan teknik purposive sampling. Data dianalisis menggunakan model Miles dan Hubberman. Hasil penelitian menunjukkan peran nenek dalam pengasuhan lebih besar karena orang tua anak dalam penelitian ini mencari nafkah. Orang tua dan nenek kurang memberi stimulasi untuk perkembangan bahasa anak. Orang tua dan nenek juga membatasi anak untuk belajar berkomunikasi. Akibatnya, anak belum mampu untuk melakukan komunikasi sederhana dan baru dapat mengucapkan beberapa kata, seperti "emoh", "dah", "ma", "um", "a". Penelitian ini menggambarkan resiko dari penerapan pengasuhan permisif orang tua dan anak terhadap perkembangan bahasa anak.
\end{abstract}

Kata kunci: komunikasi, pencapaian bahasa, pengasuhan permisif, pola asuh, stimulan

\section{Risk of Permissive Parenting by Parents and Grandmother on Child's Language Achievement}

\begin{abstract}
A child's language achievement is influenced by several factors, one of them is parenting. This study deals with the language achievement of a 2-year-old child in a family in Samirono, Yogyakarta raised by parents and grandmother with permissive parenting. The research aimed to describe how the permissive parenting of grandmother and parents influence a child's language achievement. This study used a qualitative model with a case study approach. Data were collected through interviews and observation. Informants in this study were four people based on purposive sampling. Data were analyzed using Miles and Hubberman models. The results of the study indicate that the role of the grandmother was greater because the child's parents work hard for their living. Parents and grandmothers provide less stimulation for children's language development. Parents and grandmothers also limit their children's learning to communicate. Consequently, the child has not been able to interact in simple communication and can only say a few words, such as "emoh", "dah", "ma", "um", "a". This study describes the risks of applying permissive parenting of parents and children to children's language development.
\end{abstract}

Keywords: communication, language achievement, parenting, permissive parenting, stimulant

\section{PENDAHULUAN}

Keluarga adalah lingkungan pertama anak dididik dan diasuh. Sikap, nilai, dan prinsip yang ditiru oleh anak berasal dari keluarga. Sebagai pondasi utama yang akan membimbing anak, keluarga seharusnya memiliki value yang baik untuk ditiru karena anak di usia dini adalah peniru yang ulung. Keluarga berperan penting dan dominan dalam upaya tumbuh dan kembang anak (Yusuf, 2004).

Anak adalah titipan dari Tuhan untuk dididik, dirawat, serta dijaga untuk dapat menebar manfaat kepada sesama. Anak merupakan generasi penerus kehidupan bangsa. Oleh karena itu, perlu adanya upaya pembinaan dan pengasuhan yang tepat untuk melatih anak menjadi manusia yang kompeten dan 
kompetitif. Anak terlahir dalam keadaan fitrah (suci), lingkungan di sekitar anak yang menempa dan membentuk anak. Orang di lingkungan sekitar anak memegang peranan penting dalam mencetak anak untuk menjadi bibit unggul di masa mendatang (Aisyah, 2019; Silahuddin, 2016).

Panca indera yang pertama kali berfungsi pada anak adalah pendengaran. Anak mendengar, menyerap, dan mehamami kata dari keluarga terdekatnya, yakni ibu, bapak, kakak, adik, kakek, dan nenek yang berinteraksi langsung dengan anak. Proses mendengar, menyerap, dan mehamami apa yang dikatakan orang dewasa di sekitarnya memengaruhi anak dalam mempraktikkan kosakata dalam ungkapan sehari-hari. Anak belajar bahasa melalui interaksi dengan orang dewasa disekitarnya. Ketika anak salah menyebutkan kata, lalu dibenarkan oleh ibunya; anak akan belajar dan tidak mengulangi kesalahan yang sama. Pemerolehan bahasa yang didapatkan oleh anak terjadi secara tidak sadar, implisit, dan informal (Fatmawati, 2015; Suardi, Indah, Syahrul, \& Asri, 2019; Tussholekha, 2015). Oleh karena itu, masa usia dini adalah masa yang penting dalam memberikan stimulasi aspek perkembangan bahasa anak.

Anak usia dini merupakan periode perkembangan anak yang mengalami perkembangan yang sangat pesat. Periode ini juga disebut periode golden age (masa keemasan anak) atau masa ketika anak mampu menyerap lebih cepat dari yang dilihat, dirasa, didengar, dan diraba. Masa ini sangat tepat digunakan untuk mengokohkan pondasi yang ada pada anak serta memberikan rangsangan yang tepat pada seluruh aspek perkembangan anak agar anak dapat berkembang secara optimal, salah satunya perkembangan bahasa.

Bahasa bagi anak usia dini berperan sebagai alat untuk mengekspresikan dirinya dan diwujudkan atau diikuti dengan bentuk ekspresi nonverbal. Rasa lapar, misalnya, ditunjukan dengan menangis; dan jika merasa bahagia maka ia akan tersenyum. Kemampuan bahasa anak berperan penting dalam perkembangan. Dengan berbahasa, anak dapat mengutarakan keinginan, pendapat, menyampaikan perasaannya, serta pikirannya kepada orang lain. Bahasa merupakan aspek terpenting dalam kehidupan manusia dan digunakan sebagat alat komunikasi antarmanusia agar seseorang dapat dimengerti dan dipahami maksud pikirannya (Satrianingrum, Yulsyofriend, \& Ismet, 2020). Bahasa dapat bentuk lisan maupun tulisan, dan berfungsi membuat interaksi menjadi bermakna (Amelin, Ramadan, \& Gani, 2019; Sebayang, 2018). Sehingga dengan adanya bahasa, manusia dapat berkooperasi serta mengidentifikasi diri.

Orang tua dan lingkungan yang menjadi faktor pendukung dalam pengembangan aspek anak. Pada periode anak usia dini, anak lebih banyak berinteraksi dengan keluarga. Oleh karenanya, peran keluarga untuk menyokong perkembangan anak sangat dominan. Jika keluarga terlambat dalam memberikan stimulasi perkembangan bahasa anak maka anak akan terhambat dalam perkembangan bahasanya di masa yang akan datang (Khoiriyah, Ahmad, \& Fitriani, 2016).

Secara teori, pencapaian bahasa anak pada umumnya di usia 2 tahun yang dapat teramati ialah mengerti kata "aku" dan "kamu", mengucapkan dua kalimat, dapat menggunakan lebih dari 50 kata, mengikuti kata-kata jargon, memberikan nama pada setiap gambar atau benda, dan juga menyebut diri sendiri dengan menyebut namanya (Australian Government, 2015; Scharf, Scharf, \& Stroustrup, 2016). Pengaruh gaya pengasuhan memiliki dampak terhadap perkembangan bahasa anak. Gaya pengasuhan yang baik akan memberikan efek yang baik terhadap perkembangan bahasa anak, begitupun sebaliknya. Hal tersebut disebabkan karena gaya pengasuhan orang tua memberikan kontribusi nyata terhadap aspek perkembangan anak, khususnya bahasa (Bingham, Jeon, \& Kwon, 2017; Putri, Murti, \& Indarto, 2016; Wijayanti, Wedikadigunawan, \& Murti, 2018).

Anak usia dini memiliki tahapan-tahapan dalam perkembangan bahasa. Ada beberapa tahap perkembangan bahasa anak, yakni: 1) menangis; 2) cooing (pada umur 3 bulan); 3) babbling (umur 6-10 bulan); 4) mengembangkan kata dan kalimat (umur 1-2 tahun); dan 5) menguasai bahasa seperti orang dewasa (umur 2-5 tahun) (Beaver, Wyatt, \& Jackman, 2017). Selain itu, juga ada tahap linguistik yang dialami oleh anak usia dini (Zubaidah, 2004). Pada masa bayi, anak dapat mengucapkan kata-kata, seperti "mama" dan "papa". Selanjutnya, saat usia 12 bulan, anak dapat menggunakan tiga hingga enam kata. Pada usia 12 sampai 18 bulan, anak dapat menggunakan tiga sampai dengan 50 kata. Usia 2 tahun sampai dengan 3 tahun anak dapat menerima bahasa dan dapat berkomunikasi dengan menggunakan kosa kata yang telah ia capai hingga 50 kata. Hal ini 
dipertegas dari penelitian yang menyebutkan bahwa anak usia 2 tahun dalam perkembangan bahasanya dapat mengikuti dua langkah kalimat perintah sederhana, mengerti konsep "aku" dan "kamu", menunjuk lima sampai sepuluh gambar, dapat menggunakan kata dalam bentuk kalimat sederhana (benda + kata kerja), menggunakan lebih dari 50 kata, dapat menamai 3 gambar, serta menunjuk diri sendiri dengan nama (Scharf et al., 2016).

Penelitian yang dilakukan Hollysa (2018) menunjukan bahwa usia anak 1,5 hingga 2 tahun sudah mulai dapat mengucapkan katakata yang jelas seperti "unda" (Bunda), "anyah" (Ayah), "mamam" (makan), dan "mik" (minum susu). Hollysa (2018) juga menjelaskan bahwa perkembangan bahasa setiap anak berbeda; ada yang berkembang secara pesat dan ada juga yang lambat. Hal ini dipengaruhi oleh beberapa faktor, yakni usia anak, sosial ekonomi dan lingkungan sosial keluarga, serta kemampuan orang tua, nenek, dan lingkungan sekitar anak yang aktif memberikan stimulasi dan pengasuhan yang diimplementasikan (Hollysa, 2018). Meskipun pada penelitian lainnya tidak ditemukan hubungan antara sosial ekonomi dengan perkembangan bahasa anak (Safitri, 2017).

Pengasuhan yang diterapkan orang tua dan lingkungan kepada anak akan berpengaruh pada pencapaian bahasa anak. Penelitian sebelumnya yang menggali korelasi pola asuh orang tua dengan kemampuan bicara anak yang dilakukan oleh Wangti dan Rosana (2013) menunjukkan bahwa adanya hubungan signifikan antara pola asuh orang tua dengan kemampuan anak berbicara. Pengasuhan melibatkan tata cara, perilaku, dan sikap orang dewasa yang terlibat di sekeliling anak dalam memberikan perlakuan untuk mengembangkan potensi anak ke depan (Clarke \& Stewart, 2006; Ganevi, 2013).

Gaya pengasuhan yang diterapkan oleh orang tua merupakan gambaran secara tetap dalam menuntun, mengawasi, memberi petunjuk dan memelihara anak. Baumrind (1971) menjelaskan ada empat jenis gaya pengasuhan yang dilakukan oleh orang tua. Pertama otoriter, yaitu orang tua memegang peran kendali terhadap anak. Pada gaya pengasuhan ini, anak wajib menaati peraturan yang telah dibuat dari orang tua, walaupun anak tidak menyukainya. Kedua otoritatif, gaya pengasuhan ini diidentifikasi dengan adanya diskusi hangat antara orang tua dengan anak dan orang tua menempatkan posisi yang sejajar dengan anak. Ketiga permisif, yaitu gaya pengasuhan yang menempatkan anak menjadi pusat kekuasaan (child-center). Pada pola asuh ini orang tua akan menuruti semua keinginan anak (Santrock, 2013).

Pola pengasuhan permisif adalah perlakuan dilakukan oleh orang tua yang memberikan kesempatan kepada anak seluas-luasnya, tanpa adanya batasan yang mengikat. Keempat mengabaikan, dalam gaya pengasuhan ini anak melakukan semua kemauannya tanpa adanya controlling dari orang tua. Gaya pengasuhan yang dilakukan dengan peran kontrol yang diberikan oleh orang tua merupakan teori dasar dari Baumrind (1966). Dalam gaya pengasuhannya, ada orang tua yang otoritatif (berwenang atas tindak tanduk anak), otoriter, dan permisif (membolehkan semuanya).

Baumrind (1971) menjelaskan bahwa gaya pengasuhan diukur dengan kehangatan orang tua, dukungan dan keterlibatannya sehingga muncul gaya pengasuhan tidak terlibat atau mengabaikan. Pengasuhan otoritatif, dicirikan dengan adanya kewenangan dan kontrol tinggi dari orang dewasa. Sebaliknya dengan pengasuhan otoriter, kewenangan rendah dan kontrol rendah dari orang tua. Sementara itu, pengasuhan permisif, dikarakteristikkan dengan adanya tingkat kewenangan tinggi dari orang tua namun kontrol serta tuntutan yang diberikan rendah. Pengasuhan tidak terlibat (uninvolved), dicirikan dengan orang tua yang memiliki wewenang dan kontrol rendah (Hoskins, 2014). Dalam temuan beberapa penelitian, gaya pengasuhan permisif terlihat kurangnya keterlibatan antara orang dewasa dan anak, serta tidak adanya aturan yang mengikat untuk dijalankan oleh anak, kendali dan kontrol dibawah wewenang anak (Baumrind, Larzelere, \& Owens, 2010; Hoskins, 2014).

Gaya pengasuhan yang diterapkan oleh orang tua dapat dipengaruhi oleh beberapa faktor, seperti latar belakang pendidikan, status sosial ekonomi, pendapatan, dan pengalaman dalam merawat dan menjaga anak, perbedaan etnis dan budaya, dan tingkat stress orang tua (Santrock, 2013; Sulistino, 2016; Tridhonanto, 2014; Winarti, 2019). Dalam temuan Pfannesntiel dan Seltzer (1989), dipaparkan bahwa risiko pengukuran tradisional (seperti umur orang tua, tingkat pendidikan, pendapatan, status orang tua, jumlah saudara) berkorelasi kepada aspek perkembangan anak, yakni dalam aspek intelegensi, pencapaian, dan perkembangan bahasa. Suryanda dan Rustati (2019) dan Tasu'ah (2013) telah banyak mengungkapkan mengenai peran pengasuhan orang tua yang bekerja terhadap kepribadian 
anak. Hasil lain juga menunjukkan bahwa semakin muda nenek yang mengasuh maka perkembangan anak akan baik, begitu sebaliknya (Latifah, Krisnatuti, \& Puspitawati, 2016). Namun, ada juga penelitian yang menunjukkan bahwa pengasuhan oleh nenek (grandparenting) memiliki dampak yang tidak diinginkan (Hartinah, 2014; Statham, 2011).

Hasil observasi pendahuluan yang telah dilakukan pada sebuah keluarga di Samirono, Kecamatan Condong Catur, Kabupaten Sleman, Yogyakarta memberi gambaran bahwa orang tua dan nenek kurang sensitif terhadap perkembangan bahasa anak. Orang tua dan nenek menganggap anak akan dapat berbahasa dengan sendirinya seiring dengan berjalannya waktu. Peneliti juga mendapat gambaran bahwa orang tua dan nenek tidak memberikan stimulasi perkembangan bahasa anak dengan optimal. Anak dikekang di rumah tanpa diberikan keluasan bermain dengan teman-temannya yang lain. Responden di usia 2 tahun belum dapat mengucapkan kata-kata sederhana dengan jelas. Dalam melakukan interaksi dengan orang dewasa sekitar, anak hanya menunjuk sesuatu dengan tangannya.

Oleh karena itu, penelitian ini bertujuan mengidentifikasi gaya pengasuhan orang tua dan nenek dan menggambarkan hubungan antara gaya pengasuhan orang tua dan nenek dengan pencapaian bahasa anak. Hal tersebut ditinjau dari berbagai aspek yang memengaruhi penerapan gaya pengasuhan. Penelitian ini mengangkat studi kasus praktek pengasuhan nenek dan orang tua yang berdampak pada pencapaian bahasa anak di bawah rata-rata, dengan kondisi bahwa anak lebih sering diasuh oleh nenek.

\section{METODE}

Penelitian ini menggunakan desain penelitian deskriptif dengan pendekatan kualitatif. Penelitian ini lebih menekankan data alamiah. Metode ini merupakan prosedur penelitian yang menghasilkan data berupa kata-kata untuk menggambarkan perilaku orang yang diamati (Bogdan \& Taylor, 1975). Pendekatan kualitatif digunakan karena peneliti ingin menggambarkan permasalahannya melalui kata-kata, sehingga mendeskripsikan secara gamblang permasalahan yang dialami oleh anak berkenaan pencapaian bahasa dengan gaya pengasuhan yang diterima dari nenek dan orang tua.

Lokasi penelitian di daerah Samirono, Kecamatan Condong Catur, Kabupaten
Sleman, Yogyakarta dipilih karena peneliti sudah berbaur selama 9 bulan dengan subjek yang diteliti. Peneliti melakukan penelitian pada subjek yang diteliti selama 6 bulan. Keluarga yang diteliti ini memiliki anak yang berusia 2 tahun. Satu rumah terdapat beberapa penghuni, yakni nenek, om dan tante, orang tua anak yang diteliti, serta tiga orang penghuni kos dalam satu rumah. Jumlah informan dalam penelitian ini adalah empat orang, yaitu ibu, ayah, nenek, dan tante dari anak yang menjadi subjek penelitian. Teknik sampling yang digunakan adalah purposive sampling untuk mewakili sejumlah informan yang mengetahui informasi yang peneliti butuhkan.

Instrumen dalam penelitian ini ialah peneliti sendiri. Pada penelitian kualitatif, peneliti menjadi key instrument yang bisa menentukan dan mengumpulkan fakta-fakta di lapangan yang merupakan data dan mengkategorikan sesuai dengan tujuan penelitian (Xu dan Storr, 2012). Metode pengambilan data dilakukan melalui observasi dan wawancara. Wawancara digunakan untuk memeroleh, menggali, serta memperkuat informasi lebih jauh. Agar pengumpulan data lebih mendalam dan dapat mengetahui informasi lebih dari responden, wawancara digunakan sebagai teknik pengumpulan data (Sugiyono, 2017).

Observasi juga turut dilakukan. Peneliti mengamati langsung pola asuh yang diberikan oleh orang tua dan nenek kepada responden. Aspek yang diamati saat melakukan observasi ialah kegiatan sehari-hari anak dan orang tua (jenis kegiatan yang dilakukan dan jenis stimulasi yang diberikan), lalu kegiatan anak dan nenek (jenis kegiatan dan jenis stimulasi yang diberikan). Hal ini dimaksudkan untuk melihat pencapaian bahasa anak sebagai dampak dari pengasuhan yang diterapkan. Dengan pengamatan yang dilakukan pada orang tua dan nenek, data yang diperoleh dapat digunakan untuk memberikan kesimpulan atau diagnosis (Herdiansyah, 2014).

Selanjutnya, data dicek melalui uji triangulasi untuk meningkatkan validitas kesimpulan. Hal ini dilaksanakan dalam tiga tahap untuk pengecekan ulang terhadap sumber yang dimintai keterangan (Moelong, 2012). Analisis data menggunakan model Miles dan Huberman dengan beberapa tahapan, yakni: 1) pengorganisiran data melalui wawancara dan observasi pada sumber, yang dilakukan dengan metode wawancara kepada orang tua dan nenek dan observasi partisipasi, dengan mengamati secara langsung interaksi di keluarga yang menjadi subjek penelitian; 2) 
reduksi data, dengan menyeleksi dan menyajikan data mengenai interaksi anak dengan memberikan gambaran yang jelas dan tajam; 3) penyajian data, yaitu pengungkapan secara naratif dan memungkinkan adanya penarikan kesimpulan dan pengambilan tindakan, sehingga data tersusun dan terorganisir; dan 4) verifikasi, dilakukan untuk mengecek temuan berupa gambaran yang belum jelas, lalu difokuskan dan disusun secara sistematik dalam bentuk naratif maka kesimpulan yang dikemukakan merupakan kesimpulan yang kredibel (Miles \& Huberman, 1992; Sugiyono, 2010).

\section{HASIL}

\section{Gaya Pengasuhan Orang Tua}

Orang tua responden (ayah berusia 27 tahun dan ibu berusia 26 tahun) memiliki pendidikan terakhir yakni SMA. Aktivitas sehari-hari orang tua menjaga warung di rumah. Pemasukan yang didapat dalam sebulan berkisar $\leq$ Rp800.000,00. Nenek responden terkadang masih memberikan bantuan kepada orang tua responden, seperti bantuan popok bayi, susu dan bubur untuk responden dan adiknya. Responden terkadang meminta sesuatu dengan cara menangis sehingga orang tua mengikuti keinginannya untuk meredam tangisan. Ataupun ketika mengajak responden melakukan sesuatu, orang tua harus mengulurulur waktu sampai responden mau melakukannya.

Saat orang tua bermain handphone, responden juga merengek untuk bermain handphone. Orang tua pun memberikan keinginan responden dan membiarkan responden tanpa pengawasan. Di lain kesempatan, saat responden dan ibu sedang di kamar, ibu responden hanya memerhatikan handphone dan responden pun sibuk dengan mainannya sambil mengoceh sendirian.
Ibu respoden sebagai informan menyatakan agar responden tetap anteng, ibu pun memberikan apa yang diinginkan responden, seperti handphone, seperti yang diungkapkannya, "daripada nangis lama-lama, Mba. Kasihan. Yo uwes, aku kasih HP aja". "Kadang $\mathrm{K}$ (responden) sama aku, Mba. Namun kalau di rumah ibu (Nenek K), lebih banyak sama ibu, Mba".

Ibu tidak melarang responden untuk bermain di luar rumah. Namun, karena mengikuti perintah Nenek responden, ibu responden membatasi responden untuk bermain diluar, seperti yang diungkapkan ibu responden, "kadang $\mathrm{K}$ (responden) aku ajak ke tetangga sebelah kok, Mba. Tapi ya kadang dirumah aja, takutnya nanti ada motor lewat atau bagaimana. Aman dalam pagar, Mba”.

Gambar 1 memperlihatkan, perlakuan atau stimulasi yang diberikan orang tua dan nenek dapat memberikan dampak positif terhadap perkembangan bahasa anak. Orang tua memberikan stimulasi kepada responden yakni dengan menanyakan kembali apa yang dimaksud responden, seperti yang diungkapkan sang lbu, "ya biasanya kalau dia ngomong, aku suruh biacara yang jelas, Mba. 'Ngomong opo toh Nok? Ngomong yang jelas'. Tapi kan masih kecil, palingan aku luruskan kata-katanya, Mba".

Saat waktu luang, ibu responden memberikan stimulasi dengan bernyanyi bersama. Ibu responden tidak risau dengan perkembangan bahasa responden yang belum lancar, sebab nenek responden pernah memberitahu bahwa ayah responden dulu mengalami hal yang serupa, "setidaknya ibu (Nenek) pernah bilang kalau ayah $\mathrm{K}$ juga lambat ngomong tapi jalan cepat. Tapi setidaknya, walau $\mathrm{K}$ belum bisa ngomong jelas, tapi $\mathrm{K}$ paham kok omongan kita".

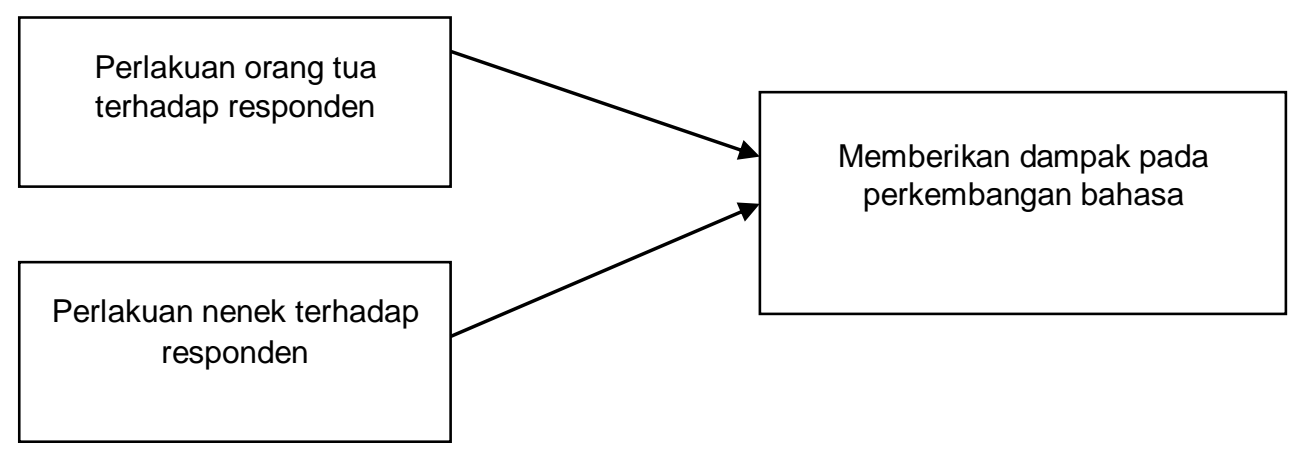

Gambar 1 Framework pengasuhan orang tua dan nenek terhadap bahasa responden 


\section{Gaya Pengasuhan Nenek}

Nenek responden berumur 45 tahun dengan pendidikan terakhir sekolah menengah atas. Nenek responden lebih banyak berada di rumah dan terkadang mengisi kegiatan organisasi di lingkungannya. Catatan temuan dalam penelitian ini, responden menghabiskan banyak waktu bersama nenek. Dalam sehari nenek dan responden menghabiskan waktu lebih kurang 19 jam.

Responden yang diteliti adalah cucu pertama, sehingga responden diperlakukan sangat spesial oleh nenek. Perlakuan ini tampak dari tindakan nenek yang selalu berinisiatif dalam melakukan apapun kepada responden. Misalnya, ketika responden menunjuk mainan, kemudian nenek langsung mengambilkannya tanpa menanyakan terlebih dahulu apa yang ditunjuk. Ketika $\mathrm{K}$ menangis saat bermain dengan tantenya, nenek langsung memarahi tante. Hal tersebut dilakukan untuk menghibur responden agar tidak menangis.

Perbandingan gaya pengasuhan yang diterapkan orang tua dan nenek kepada $\mathrm{K}$ bisa dilihat pada Tabel 1.

Tabel 1 Pengasuhan yang dilakukan orang tua dan nenek kepada responden

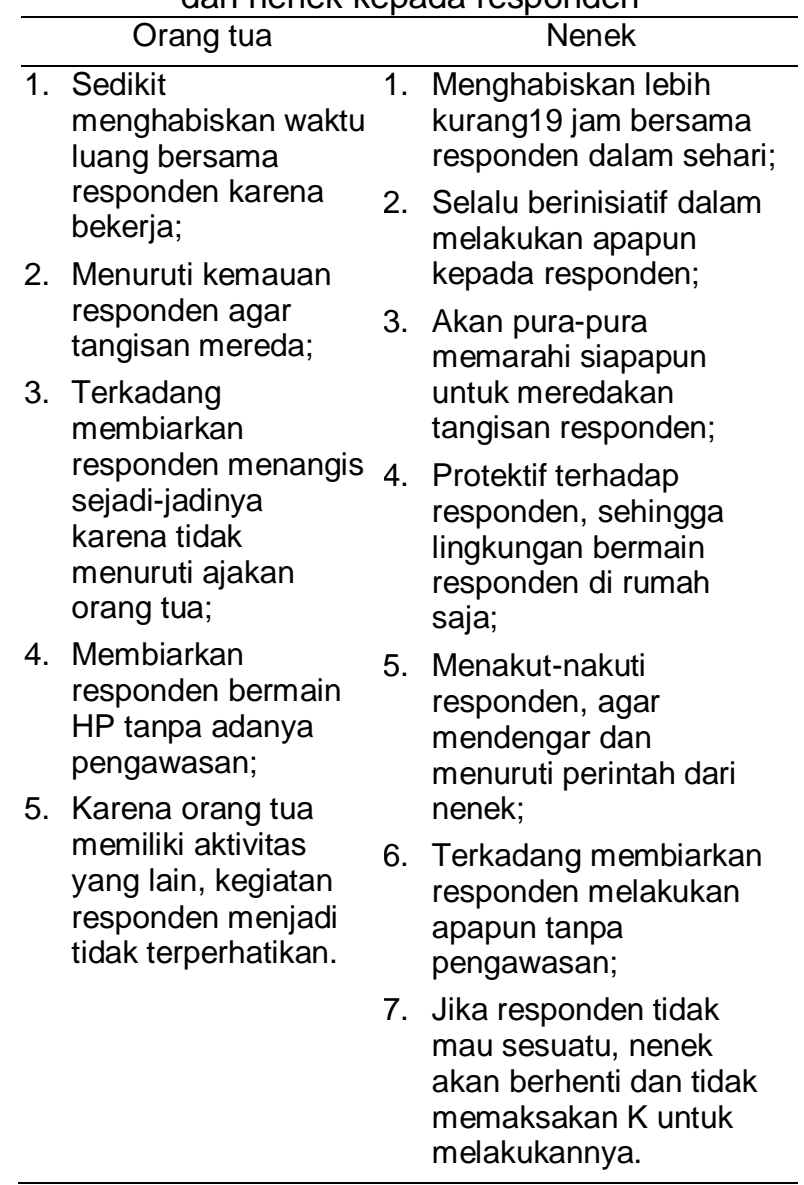

Dalam keseharian, responden dilarang untuk bermain di luar sehingga responden hanya mengamati dari dalam pagar. Nenek sangat protektif terhadap responden. Agar responden menuruti perintah dari nenek, nenek menakutnakuti responden. Seperti contoh, ketika responden dilarang ke dapur, nenek akan memberitahu ia akan dimakan oleh kecoa. Hal inilah yang membuat responden mengurungkan niatnya.

Nenek selalu mengisi waktu dengan kegiatan bersama, seperti menonton TV. Responden terkadang di luar pengawasan nenek, sehingga responden dapat menukar channel yang ia suka. Dalam kegiatan lainnya, nenek responden selalu menuruti dan melepaskan apa yang tidak disukai oleh responden. Jika responden melepehkan nasi dari mulutnya, nenek merasa responden tidak suka nasi dan buru-buru menggantikan dengan susu. Alasannya adalah agar responden tetap mendapati nutrisi yang baik. Selain itu, nenek tidak terlalu memaksakan keinginannya dan mengikuti apa yang menjadi kemauan responden. Namun, jika responden berulah, nenek akan mengunci pintu kamar bersama responden, agar responden tidak leluasa bergerak kemana-mana.

Agar anak dan cucu tidak merasakan penderitaan nenek waktu dulu, apapun yang diinginkan anak ataupun cucunya akan dipenuhi Nenek responden, seperti yang diungkapkannya, "Wong aku dulu serba kekurangan, Mba. Jadi kasihan aku kalau $\mathrm{K}$ minta ini, ngga aku kasih". Nenek responden tidak risau dengan keterlambatan berbicara cucunya, karena anaknya (Ayah responden) dulu juga mengalami hal yang sama, "Nanti kalau udah gede, K bisa ngomong kok, Mba. Bapaknya dulu juga gitu..".

\section{Pencapaian Bahasa Anak}

Ketika responden mengucapkan kata-kata, orang tua hanya menirukan apa yang responden sebutkan tanpa memperbaiki cara pengucapannya. Selain itu, terkadang orang tua membiarkan responden mengoceh sendiri karena orang tua merasa tidak mengerti apa yang diucapkan. Orang tua juga terkadang meminta responden untuk berbicara dengan jelas, "ngomong tu yang jelas toh, Nok.." tanpa memberikan stimulasi apapun. Adapun orang tua mengajak responden berinteraksi, namun juga meniru ucapan responden yang tidak jelas. Bahasa yang digunakan orang tua dan nenek dalam mengajak responden berinteraksi cenderung menggunakan bahasa Indonesia 
dengan mencampurkan kosa kata bahasa Jawa.

Stimulasi yang diberikan nenek dalam pencapaian bahasa responden masih belum optimal. Orang tua dan nenek responden percaya bahwa sejalan beriringnya usia, responden akan dapat berbicara dengan baik. Nenek terkadang memarahi Om responden ketika Om responden mengajak ia berinteraksi, "kamu udah tahu si K belum bisa bicara, malah diajak ngobrol'. Nenek merasa apa yang dilakukan Om responden hanya suatu hal yang sia-sia saja. Setiap benda apapun ditunjuk oleh responden saat di rumah, nenek secara sigap langsung mengambilkan, tanpa bertanya kepada responden apa yang dimaksud. Ketika responden menangis, nenek dengan sigap langsung membuatkan susu agar tangis responden mereda dan menidurkannya. Responden di umurnya yang 2 tahun, dapat mengucapkan "ma", "moh (tidak)", "um", "a". Lebih lanjut, Tabel 2 menunjukkan perbandingan perkembangan bahasa anak menurut Milestone (Australian Government, 2015) dan perkembangan bahasa responden di lapang.

Ada empat kategori gaya pengasuhan yang dikemukakan Baumrind (1971), yakni otoriter, otoritatif, permisif dan mengabaikan. Gaya pengasuhan yang diterapkan oleh orang tua dan nenek pada responden ialah gaya pengasuhan permisif. Hal ini terlihat dari cara pengasuhan orang dewasa yang menuruti semua keinginan anak tanpa memberitahukan alasan atau menanyakan sebabnya. Salah satu ciri dari gaya pengasuhan permisif ialah orang tua memberikan kesempatan kepada anak seluas-luasnya tanpa adanya batasan yang mengikat serta kurangnya konsekuensi yang diterima oleh anak (Echedom, Nwankwo, \& Nwankwo, 2018).

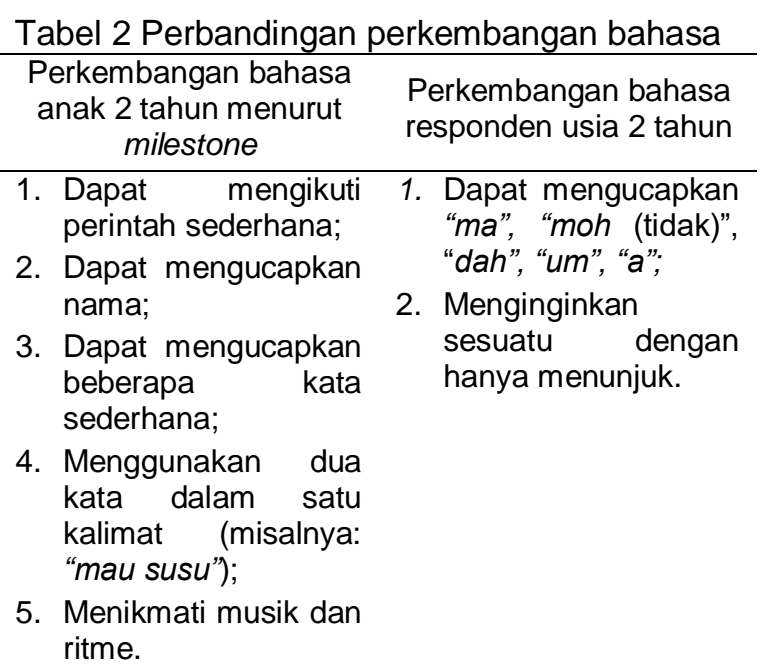

\section{PEMBAHASAN}

Kesibukan yang dimiliki oleh orang tua, membuat orang tua menitipkan anaknya kepada nenek (Silalahi \& Meinarmo, 2010). Fakta yang ditemukan di lapangan, waktu yang dimiliki anak-nenek lebih panjang dibanding waktu anak-orang tua. Penelitian sebelumnya menemukan bahwa 75 persen cucu diasuh oleh nenek dari umur 0 sampai 3 bulan; 76,92 persen nenek berada pada satu tempat tinggal yang sama dengan anak dan cucunya; 59,62 persen nenek memiliki waktu luang yang panjang dalam mengasuh cucunya, serta ada 6 sampai 9 kegiatan yang dilakukan oleh nenek dan cucu secara bersamaan (Latifah et al., 2016). Nenek memiliki cara sendiri untuk menyayangi cucunya dan dalam kasus dalam penelitian ini terlihat dari cara nenek yang mengikuti seluruh kemauan cucu. Dalam pengasuhan grandparenting, nenek atau kakek sangat memberikan keleluasaan pada cucu (Eriyanti, Susilo, \& Riyanto, 2019). Hal senada diungkapkan oleh Viguer, Mendelez, Valencia, Canterro dan Navaro (2010) yang mengatakan bahwa pengasuhan dari nenek dan kakek tidak terlalu ketat dan disiplin.

Pungello, Dotterer, Iruka, dan Mills-Koonce (2009) menyatakan bahwa ada faktor saat mengasuh dan interaksi serta perilaku instruksi yang negatif yang memengaruhi perkembangan bahasa anak. Nenek selalu ingin memanjakan dan menyayangi cucunya, terkadang secara berlebihan, sehingga selalu menuruti apa keinginan cucu tanpa banyak terjadi proses dialog antara keduanya. Pengasuhan permisif nenek atau kakek (grandparenting) kepada cucunya tersebut bisa dikaitkan dengan keinginan untuk memperbaiki kesalahan di masa lalu dalam mengasuh anak-anak mereka.

Hasil temuan Ristia (2016) mengenai pola asuh grandparenting menunjukan bahwa pengasuhan dari nenek atau kakek (grandparenting) pada umumnya menunjukan pola asuh permisif. Hal tersebut juga diipertegas oleh penelitian lainnya yang menemukan bahwa ada pengaruh yang diberikan pada pengasuhan yang diimplementasikan oleh nenek dan orang tua pada perkembangan dan kemandirian dan kognitif anak (Latifah et al., 2016). Hal tersbeut mempertegas bahwa pengasuhan yang dilakukan oleh orang dewasa di sekitar anak memiliki dampak yang sangat besar terhadap perkembangan anak di usia dini.

Selain gaya pengasuhan permisif, gaya pengasuhan mengekang atau otoriter walau 
tidak kentara namun terlihat pada perilaku yang ditujukan orang tua dan nenek kepada anak, yakni tidak memberikan anak respondenkebebasan dalam bermain. Ciri dari gaya pengasuhan otoriter adalah orang tua mendesak anak untuk mengikuti arahan serta menghormati pekerjaan dan upaya orang tua tanpa memberikan alasan yang jelas. Selain itu juga dikarakteristikkan dengan orang tua sebagai pusat (parent's center) dari interaksi yang terjadi antara orang tua dengan anak (Santrock, 2013). Gaya pengasuhan yang banyak mengekang atau melarang anak dapat membuat anak merasa tidak mampu dengan apa yang mereka lakukan (Mattanah, 2005).

Selain hal tersebut, gaya pengasuhan membiarkan (neglectful) juga teramati dalam penelitian pada keluarga ini. Agar anak tidak rewel dan tidak mengganggu kegiatan yang dilakukan, orang tua memberikan benda-benda yang diinginkan anak dan membiarkan ia bermain sendiri tanpa adanya pengawasan dari orang dewasa. Perilaku orang tua untuk membiarkan anak bermain sendirian tanpa adanya stimulasi tidak baik bagi perkembangan bahasanya karena tidak memberi ruang baginya untuk belajar berkomunikasi. Baumrind (1971) menyatakan ciri dari orang tua dengan gaya pengasuhan membiarkan (neglectful) ialah dengan tidak adanya keterlibatan orang tua dengan kehidupan anak. Anak dibiarkan dengan gadget yang dipegangnya, sedangkan orang tua juga sibuk dengan tugas yang ia kerjakan. Hasil temuan Pungello et al. (2009) menemukan beragam bentuk pengasuhan yang diterapkan di rumah akan memberikan pengaruh yang beragam pula terhadap perkembangan bahasa anak.

Idealnya, pada usia 2 tahun, milestone perkembangan bahasa anak diantaranya anak akan sering bertanya karena keingintahuannya tinggi, memiliki perbendaharaan kata kira-kira 200 kata, dapat mengucapkan tiga kalimat sederhana, mengulang kembali cerita pendek yang telah didengar, menamai 10 sampai dengan 15 benda, dan lain sebagainya (Karo, 2015; Mainizar, 2013; Scharf et al., 2016; Septiyani \& Hartati, 2018). Hasil penelitian yang dilakukan menemukan bahwa anak yang menjadi subjek penelitian ini baru mampu mengucapkan beberapa kosa kata (Tabel 2). Selain itu, anak belum mampu merangkai beberapa kata, hanya dapat mengucapkan kata-kata tertentu secara berulang-ulang, berkomunikasi dengan orang lain tidak menggunakan bahasa atau pun kata-kata, belum mampu mengikuti perintah sederhana. Hal-hal tersbeut sebenarnya perlu diwaspadai sebagai gangguan keterlambatan dalam perkembangan berbicara dan bahasa pada anak karena tidak sesuai dengan standar milestone perkembangan anak pada umumnya (Scharf et al., 2016).

Kondisi orang tua, salah satunya kondisi ekonomi, teramati dalam penelitian ini memengaruhi pengasuhan yang diterapkan. Keadaan sosial ekonomi mendorong orang tua untuk melakukan pekerjaan untuk memenuhi kehidupan sehari-hari dan menitipkan anak kepada nenek. Hal tersbeut menyebabkan interaksi dan komunikasi verbal antara orang tua dengan anak kurang intensif. Padahal komunikasi orang tua kepada anak bisa menjadi stimulan yang efektif untuk memicu anak belajar bahasa.

Temuan Perkins, Finegood, dan Swain (2013) menegaskan bahwa status sosial ekonomi juga memengaruhi pengasuhan orang tua, yang tentu saja juga berdampak pada aspek perkembangan anak, termasuk perkembangan bahasa. Orang tua yang bekerja keras cenderung tidak punya banyak waktu sehingga interaksi dengan anak terbatas. Penelitian sebelumnya (Latifah et al., 2016; Ristia, 2016) menyebutkan bahwa hal yang mendorong anak diasuh oleh nenek ialah karena faktor ekonomi. Akibat orang tua bekerja untuk memenuhi kebutuhan sehari-hari, nenek tergerak membantu orang tua anak agar memudahkan orang tua mencari nafkah. Anak yang terlahir dari keluarga berstatus sosial ekonomi baik memungkinkan orang tua lebih berpeluang memberikan stimulasi perkembangan bahasa anak yang lebih baik. Status sosial ekonomi yang baik membuat orang tua dapat merangsang bahasa anak melalui penyediaan fasilitas yang dimiliki. Namun, jika anak dengan status sosial ekonomi yang rendah, keadaan tersebut membuat orang tua diharuskan untuk bekerja dan berada jauh dari anak, serta alat dan permainan yang kurang memadai dalam menunjang perkembangan bahasa anak (Candrasari, 2017).

Selain itu, orang tua yang belum memiliki pengalaman dalam merawat anak dapat menjadi salah satu sebab salahnya pengasuhan yang diberikan. Temuan Pfannesntiel dan Seltzer (1989) menjelaskan bahwa risiko penagsuhan yang dilakukan dengan pengukuran tradisional (seperti umur orang tua, tingkat pendidikan, pendapatan, single parent versus orang tua lengkap, jumlah saudara) berkorelasi kepada aspek perkembangan anak, salah satunya aspek perkembangan bahasa. Pengasuh yang 
berperan dalam menjaga, mendidik, dan merawat anak membutuhkan pengetahuan dan keterampilan yang mumpuni (Karo, 2015). Hal ini disebabkan karena usia dini merupakan momentum yang tepat untuk mengembangkan potensi anak secara optimal. Adanya ikatan atau hubungan yang kuat serta penerapan pola pengasuhan yang tepat antara pengasuh dengan anak akan berdampak positif terhadap perkembangan berbahasa anak (Wangti \& Rosana, 2013). Gaya pengasuhan yang positif mampu memberikan hasil optimal terhadap tumbuh kembang anak. Gaya pengasuhan yang positif sangat signifikan dalam memengaruhi segala aspek perkembangan anak, termasuk juga dengan perkembangan bahasa anak (Santrock, 2013). Dengan demikian, perbaikan gaya pengasuhan dapat menjadi alternative dalam meningkatkan perkembangan bahasa anak.

\section{SIMPULAN DAN SARAN}

Penelitian ini menggambarkan resiko dari penerapan pengasuhan permisif orang tua dan anak terhadap perkembangan bahasa anak. Sikap orang tua yang membiarkan anak untuk bermain Handphone tanpa adanya pengawasan dan juga sikap nenek yang selalu berinisiatif dalam melakukan apapun kepada responden ternyata dapat menurunkan pencapaian bahasa anak. Pengasuhan permisif yang diterapkan orang tua dan nenek tidak mampu memberikan stimulan yang signifikan untuk merangsang perkembangan bahasa anak secara optimal. Hal tersebut menyebabkan perkembangan bahasa anak belum memenuhi standar bahasa anak umur 2 tahun pada umumnya.

Berdasarkan hasil penelitian, penelitian ini menyarankan agar orang tua dan nenek sebaiknya menerapkan gaya pengasuhan yang demokratis. Perkembangan bahasa anak dapat dirangsang melalui pengasuhan baik yang diberikan oleh orang tua dan nenek. Hasil penelitian juga mengindikasikan diperlukannya stimulus-stimulus dari orang tua dan nenek yang lebih optimal dalam memberikan stimulasi bahasa anak. Penelitian ini hanya menggambarkan resiko yang ditimbulkan akibat dari penerapan pengasuhan permisif terhadap perkembangan bahasa anak secara deskriptif pada sebuah kasus pengasuhan yang dilakukan bersama antara orang tua dan nenek, dengan pengasuhan nenek yang lebih dominan. Oleh karena itu, perlu ditindaklanjuti dengan pendalaman kasus terkait pengetahuan dan keterampilan orang tua dan nenek dalam menerapkan pengasuhan yang positif yang mampu memberikan stimulasi perkembangan bahasa anak di usia dini.

\section{DAFTAR PUSTAKA}

Aisyah, S. (2019). Pendidikan fitrah dalam perspektif hadist. Jurnal IImiah Pendidikan Guru Madrasah Ibtidayah, 9(1), 51-64. doi:10.18592/aladzkapgmi.v9i1.3007

Amelin, R., Ramadan, S., Gani, E. (2019). Memahami bahasa anak usia 14 bulan melalui unsur "non-linguistik". Jurnal Obsesi, 3(1), 146-152. doi:10.31004/obsesi.v3i1.155

Australian Government. (2015). Developmental milestone and the early years learning framework and the national quality standards. New South Wales, AU: Community Child Care Co-operative Ltd.

Baumrind, D. (1966). Effects of authoritative parental control on child behavior. Child Development, 37(4), 887-907. doi: https://doi.org/10.2307/1126611

Baumrind, D. (1971). Current pattern of parental authority. Developmental Psychology Monograph, 4(1), 1-103. doi:https://doi.org/10.1037/h0030372

Baumrind, D., Larzele, R. E., \& Owens, E. B. (2010). Effects of preschool parent's power: Assertive patterns and practices on adolescent development. Parenting, 10(3), 157-201. 15295190903290790

Beaver, N., Wyatt, S., \& Jackman, H. (2017). Early education curriculum. Boston, US: Nelson Education, Ltd.

Bingham, G. E., Jeon, H. Y., \& Kwon, K. A. (2017). Parenting style and home literacy opportunities: Associations with children's oral language skills. WILEY, 26(5), 1-18. doi:https://doi.org/10.1002/icd.2020

Bogdan, R., \& Taylor, S. J. (1975). Introduction to qualitative research methods: $A$ phenomenological approach to the social sciences. New York, USA: Wiley.

Candrasari, A. (2017). Pengaruh lingkungan terhadap perkembangan bahasa anak. Paper presented at The $5^{\text {th }}$ URECOL Proceeding, Yogyakarta.

Clarke, \& Stewart, A. (2006). What have we learn: Proof that families matter, policies for family and children, prospects for future research. New York, USA: Cambridge University Press. 
Echedom, A. U., Nwankwo, E., \& Nwankwo, T. V. (2018). Influence of authoritative, authoritarian, permissive, and the uninvolved parenting styles on the reading attitudes of students in Anambra State, Nigeria. Library Research Journal, 2(1), 1 25. doi:https://10.15640/jlis.v6n2a1.

Eriyanti, I. O., Susilo, H., \& Riyanto, Y. (2019). Analisis pola asuh grandparenting dalam pembentukan karakter anak TK. Jurnal Pendidikan untuk Semua, 3(1), 9-16.

Fatmawati, S. R. (2015). Pemrolehan bahasa pertama menurut tinjauan psikolinguistik. Jurnal Lentera, 18(1), 63-75.

Ganevi, N. (2013). Pelaksanaan program parenting bagi orang tua dalam menumbuhkan perilaku keluarga ramah anak (studi deskriptif di pendidikan anak usia dini Al-lkhlas Kota Bandung). Jurnal Pendidikan Luar Sekolah, 9(2), 1-11.

Hartinah, R. (2014). Perilaku anak dalam pola asuhan kakek nenek. Padang, ID: STKIP PGRI Sumatera Barat.

Herdiansyah, H. (2014). Metodologi penelitian kualitatif. Jakarta, ID: Salemba.

Hollysa, A. (2018). Pemerolehan bahasa indonesia pada anak usia 0-2 tahun: Kajian psikolinguistik. JURNAL LINGUA, 15(1), 45-52. doi: https://doi.org?DOI;10.30957

Hoskins, D. H. (2014). Consequences of parenting on adolescent outcomes. Societies Journal, 4(3), 506-531. doi:https://10.3390/soc4030506.

Karo, M. Br. (2015). Hubungan pengetahuan dan sikap ibu terhadap perkembangan bahasa anak usia 1-3 tahun (Toddler) di Sekolah Nisrina Jati Asih Kota Bekasi Tahun 2013. Jurnal IImiah Widya, 4(3), 6872.

Khoiriyah., Ahmad, A., Fitriani, D. (2016). Model pengembangan kecakapan berbahasa anak yang terlambat berbicara (speech delay). Jurnal IImiah Mahasiswa Pendidikan Anak Usia Dini, 1(1), 36-45.

Latifah, E. W., Krisnatuti, D., \& Puspitawati, H. (2016). Pengaruh pengasuhan ibu dan nenek terhadap perkembangan kemandirian dan kognitif anak prasekolah. Jurnal IImu Keluarga \& Konsumen, 9(1), 21-32. doi:https://doi.org/10/24156 /jikk.2016.9.1.21

Mainizar. (2013). Peranan orang tua dalam pembinaan dan pengembangan bahasa pada anak usia 2-6 tahun. Jurnal Marwah,
12(1), $\quad 91 . \quad$ doi:https://10.2401 4/marwah.v12i1.516

Mattanah, J. F. (2005). Authoritative parenting and the encouragement of autonomy: The family context of parenting in children's adaptation to elementary school. Monographs in parenting series. Mahwah, NJ: Lawrence Erlbaum Associates.

Perkins, S. C., Finegood, E. D., Swain, J. E. (2013). Poverty and language development: Roles of parenting and stress. Innovation Journal in Clinical Neuroscience, 10(4), 10-19.

Pfannesntiel, J. C., \& Seltzer, D. A. (1989). New parents as teacher: evaluation of early parent education program. Early Childhood Research Quarterly Journal, 4(1), 1-18. doi:https://doi.org/10.1016/S08852006(89)90025-2

Pungello, E. P., Dotterer, A. M., Iruka, I. U., \& Mills-Koonce, W. R. (2009). The effect of socioeconomic status, race, and parenting on language development in early childhood. Developmental Psychology Journal, 45(2), 544-557. doi:https://doi.org/ $10.1037 / \mathrm{a} 0013917$

Putri, R. A., Murti, B., \& Indarto, D. (2016). Effect of nurturing at child care center on gross and fine motoric, language and social development in Unggaran Barat Subdistrict, Unggaran. Journal of Maternal and Child Health, 2(1), 1-9. doi:https:// 10.26911/thejmch.2017.02.01.01

Ristia, R. (2016). Pola asuh grandparenting. Yogyakarta, ID: UIN Sunan Kalijaga.

Safitri, Y. (2017). Faktor-faktor yang berhubungan dengan perkembangan bahasa balita di UPTD kesehatan Baserah tahun 2016. Jurnal Obsesi: Jurnal Pendidikan Anak Usia Dini, 1(2), 148-155.

Santrock, J. W. (2013). Life-span development fourteenth. McGraw-Hill. New York, USA: Companies Edition Americas.

Satrianingrum, A. P., Yulsyofriend., \& Ismet, S. (2020). Metode pengenalan bahasa Inggris di Pioneer Montessori School Padang. Jurnal Diklus, 2(4), 101-111.

Scharf, R. J., Scharf, G. J., \& Stroustrup, A. (2016). Developmental milestone. Pedtriatics in Review, 37(1), 25-38.

Sebayang, S. K. (2018). Analisis pemerolehan bahasa pertama (bahasa Melayu) pada anak usia 3 tahun. Jurnal Pena Indonesia, 4(1), 106-114. 
Septiyani, M. \& Hartati, U. (2018). Pemerolehan bahasa anak-anak usia 3 dan 5 tahun dalam dialek Banyumas di Kejawang Sruweng Kebumen. Jurnal Caraka, 5(1), 123-138.

Silahuddin, S. (2016). Internalisasi pendidikan iman kepada anak dalam perspektif Islam. Jurnal Ilmiah Didaktika, 16(2), 198. doi:10.22373/jid.v61i2.595

Silalahi, K., \& Meinarmo, E. (2010). Keluarga Indonesia. Jakarta, ID: Rajawali Pers.

Statham, J. (2011). Grandparents providing child care. London, UK: Childhood Wellbeing Research Center.

Suardi, Indah P., R. Syahrul., \& Asri, Y. (2019). Pemrolehan bahasa pertama anak usia dini. Jurnal Pendidikan Anak Usia Dini, 3(1), 265-273. doi:https://10.310004/ obsesi.v3i1.160.

Sugiyono. (2010). Metode penelitian kuantitatif, kualitatif dan $R$ \& D. Jakarta, ID: Alfabeta.

Sugiyono. (2017). Metode penelitian pendidikan pendekatan kuantitatif, kualitatif dan $R$ \& $D$. Bandung, ID: Alfabeta.

Sulistino, E. (2016). Pengasuhan anak pada single parent (Disertasi). Bandung, ID: Universitas Pendidikan Indonesia

Suryanda \& Rustati, N. (2019). Hubungan pola asuh orang tua bekerja dengan kemandirian anak. Ners dan Kebidanan, $6(1)$, 35-43. doi:10.26699/jnk.v6i1.ART.p035-043.

Tasu'ah, N. (2013). Pengaruh kegiatan extra feeding dan pola asuh orang tua terhadap kemandirian anak. Pendidikan Usia Dini, 7(2), 321-334.

Tridhonanto, A. (2014). Mengembangkan pola asuh demokratis. Jakarta, ID: Gramedia.

Tussholekha, R. (2015). Mekanisme pemrolehan bahasa pada anak usia satu dan lima tahun. Jurnal Pesona, 1(2), 5970.

Viguer, P., Melendez, J. C., Valencia, S., Cantero, M. J., \& Navarro, E. (2010). Grandparent-grandchild relationships from the children's perspective: Shared activities and socialization styles. The Spanish Journal of Psychology, 13(2), 708-717. s1138741600002377.

Wangti, D. W. \& Rosana, E. (2013). Korelasi pola pengasuhan orang tua dengan kemampuan bicara anak kelompok B TK Dharma Wanita Beringin Mojokerto. Jurnal PAUD Teratai, 2(2), 172-174.

Wijayanti, A., Wekadigunawan, C. S. P., \& Murti, B. (2018). The effect of parenting style, bilingual school, social environment, on speech and language development in preschool children in Surakarta, Central Java. Journal of Maternal and Child Health, 03(03), 184-196. doi:https://doi.org/ 10.26911/thejmch.2018.03.03.03.

Winarti, W. (2019). Hubungan antara tingkat pendidikan orang tua dengan orientasi pola asuh anak usia dini. PROCEEDING: The Annual International Conference on Islamic Education, 4(1), 261-270.

Xu, M. A., \& Storr, G. B. (2012). Learning the concept of researcher as instrument in qualitative research. The Qualitative Report, 17(21), 1-18.

Yusuf, S. (2004). Psikologi perkembangan anak dan remaja. Bandung, ID: PT Remaja Rosdakarya.

Zubaidah, E. (2004). Perkembangan bahasa anak usia dini dan teknik pengembangannya di sekolah. Jurnal Cakrawala Pendidikan, 13(3), 459-479. doi:https://doi.org/10.21831/cp.v3i3.7600. 